\title{
PACIENTUU, PATYRUSIŲ GALVOS SMEGENŲ INSULTĄ, KASDIENIŲ VEIKLŲ ATLIKIMO IR PAŽEISTOS RANKOS FUNKCIJOS VERTINIMAS REABILITACIJOS EIGOJE BEI TAIKANT ERGOTERAPIJĄ NAMUOSE
}

\author{
Jolita Rapolienė, Laura Pivorienė \\ Lietuvos sveikatos mokslu universiteto Reabilitacijos klinika
}

Raktažodžiai: ergoterapija, ergoterapijos namų programa, galvos smegenų insultas, kairès rankos hemiparezė, savarankiškumas kasdieninėje veikloje, rankų raumenų jèga.

\section{Santrauka}

Insultas - tai liga, sukelianti neiggalumą, dèl sutrikusios kraujotakos smegenyse, liga, sukelta dèl cerebrovaskulinių sutrikimų, širdies ligų ar cukrinio diabeto (1). Daugelio šalių gyventojų dažniausia mirties priežastis yra lètinès neinfekcinès (LNL), ypač širdies ir kraujagyslių, ligos (ŠKL).

Dažniausia insulto pasekmė yra vienos kūno pusès paralyžius, dèl ko vystosi koordinacijos, pusiausvyros, judejimo sutrikimai.

Sergančiujų galvos smegenų insultu ergoterapija Lietuvoje tyrinejjama, tačiau yra nedaug duomenų, kaip pakinta ligonių, patyrusių galvos smegenų insultą, kasdienès veiklos bei pažeistos rankos funkcija ne tik reabilitacijos metu, bet ir tęsiant ergoterapiją namuose.

Darbo tikslas: įvertinti pacientų, patyrusių galvos smegenų insultą, kasdienių veiklų atlikimą, pažeistos rankos funkciją reabilitacijos eigoje bei taikant ergoterapiją namuose.

Metodika: tyrime dalyvavo 60 pacientų, kuriems buvo diagnozuotas galvos smegenų insultas dešiniajame galvos smegenų pusrutulyje. Pacientai buvo suskirstyti: 1 grupe $n=30$ tiriamujų, kuriems buvo sudaryta ergoterapijos namų programa ir 2 grupé $n=30$ tiriamujjų grįžo ị namus ir atliko tik kasdienines veiklas, be papildomos ergoterapijos programos.

Tyrimo medžiaga ir metodai. Tyrimas buvo atliekamas nuo 2016 m. rugpjūčio - 2017 m. sausio mènesio. Visiems tiriamiesiems buvo taikytas klausimynas (anketa), Funkcinio nepriklausomumo testas (FNT), dinamometrija, Frenchay parezinès rankos miklumo testas.

Rezultatai. Pacientams, patyrusiems galvos smegenų insultą, pažeistos rankos raumenų jèga atsistato greičiau taikant ergoterapijos namų programą su papildomomis ergoterpijos užduotimis.

Išvados. Visiems tiriamiesiems po pusès metų nustatytas statistiškai reikšmingas savarankiškumo pagerejjimas $(p<0,05), 1$ grupès tiriamieji gebejjo savarankiškai atlikti kasdienes veiklas ir tik atliekant sudètingesnes veiklas išliko modifikuotos pagalbos būtinybè, o 2 grupès tiriamiesiems - būtina minimali/ vidutinè kito asmens pagalba. Taip pat visiems tiriamiesiems po pusès metų rankos miklumas statistiškai reikšmingai pagerèjo $(\mathrm{p}<0,05)$. Abiejų grupių tiriamiesiems po pusės metų rankų raumenų jèga statistiškai reikšmingai padidèjo $(\mathrm{p}<0,05)$. Nustatytas statistiškai reikšmingas skirtumas tarp grupių po 6 mėnesių. Rankų miklumas statistiškai reikšmingai siejasi su parezinès rankos plaštakos raumenu jèga ir su pacientų savarankiškumu atliekant kasdienes veiklas.

\section{İvadas}

Galvos smegenų insultas - tai galvos smegenų kraujotakos sutrikimas, pasireiškiantis židininiais neurologiniais simptomais, kurie gali išlikti ilgiau kaip 24 val. nuo susirgimo pradžios (2).

Lietuvos sveikatos statistikos duomenimis (2015 m.), nuo kraujotakos sistemos ligų mirè daugiau nei pusė, t.y. 56,5 proc. gyventojų. Nuo kraujotakos sistemos ligų mire 23587 asmenys, didžiausią jų dali sudare asmenys, mirę nuo išeminès širdies ligos ( 65,8 proc.) bei cerebrovaskuliniu ligų (24,1 proc.). Didžioji dalis ( 86,8 proc.) mirusiujų nuo kraujotakos sistemos ligų buvo 65 metų ir vyresnio amžiaus asmenys (1).

Mirštamumas dèl GSI siekia 33-40 proc. (skaičiuoja- 
mas per pirmąsias 28 dienas). Vakarų Europoje nuo insulto mirštama apie 3 proc. per metus, o Rytų Europoje ir Lietuvoje mirštamumas stabilus ar nežymiai didejja. GSI sudaro 10 proc. visų vyrų ir apie 16 proc. visų moterų mirčių (3). Didelei daliai asmenų, patyrusių galvos smegenų insultą, išlieka judejjimo, apsitarnavimo, pažinimo funkcijų sutrikimų, ribojančių socialinę jų veiklą, bloginančių gyvenimo kokybę. Laiku ir aktyviai pradètos taikyti sudètinès reabilitacijos priemonès pagerina ligos eigos prognozę, padeda sugrąžinti pažeistas funkcijas, išvengti komplikacijų, suteikia asmeniui galimybę maksimaliai prisitaikyti kasdienèje veikloje (4).

Darbo tikslas: ịvertinti pacientų, patyrusių galvos smegenų insultą, kasdienių veiklų atlikimą, pažeistos rankos funkciją reabilitacijos eigoje bei taikant ergoterapiją namuose.

\section{Tyrimo medžiaga ir metodas}

Tiriamujų, patyrusių galvos smegenų insultą, savarankiškumui bei parezinès rankos funkcijai ịvertinti buvo sudaryta 13 klausimų anketa. Apklausa buvo vykdoma pacientui pateikiant anketą, kurioje prašoma pažymèti jiems tinkamiausią variantą. Tiriamieji įspejjami, kad anketa anonimiška, todèl duomenys nebus paviešinti.

Funkcinio nepriklausomumo testas (FNT) (angl. Functional Independence Measure). Testas skirtas įvertinti pacientų, patyrusių GSI, savarankiškumą. Naudojant ši testą, vertinamas ligonio gebejjimas apsitarnauti, orientacija laike, gebèjimas spręsti problemas bei palaikyti socialinius santykius. Kiekvienos veiklos sutrikimas vertinamas balais - nuo 1 iki 7: 1 visiška pagalba (apsitarnavimas 0 proc.); 2 - maksimali pagalba (apsitarnavimas - 25 proc.); 3 - vidutiné pagalba (apsitarnavimas - 50 proc.); 4 - minimali pagalba (apsitarnavimas - 75 proc.); 5 - priežiūra; 6 - modifikuotas nepriklausomumas (irankis); 7 - visiškai nepriklausomas. Vertinama pagal 18-126 balų skalę.

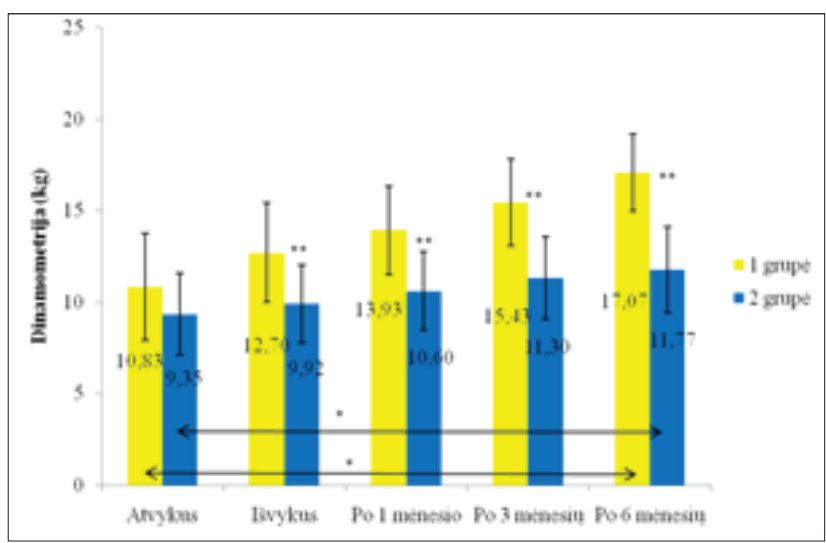

1 pav. Tiriamųų pasiskirstymas grupėse pagal pažeistos rankos raumenų jègą $(\mathrm{kg})$
Frenchay rankos miklumo testas (FRT). Šis testas vertina rankos ir plaštakos su pareze miklumą. 1. Laikant liniuotę pažeista ranka sveikaja tuo metu pagal ją nubrèžti liniją. 2. Pažeista ranka pakelti $12 \mathrm{~mm}$ skersmens cilindrą $15 \mathrm{~cm}$ nuo stalo viršaus ir jị vèl pastatyti, kad nenugriūtų. 3 . Pažeista ranka pakelti iki pusès vandens pripildytą stiklinę ir atsigerti iš jos, neapsilaistant. 4. Pažeista ranka užsegti ir nusegti skalbinių segtuką nuo vertikalioje padètyje esančio virbo (galima naudoti ir stovą su atitinkamo storio virvele). 5. Pažeista ranka imituoti plaukų šukavimąsi. Užduočių atlikimas, vertinamas laiku (s).

JAMAR ${ }^{\circledR}$ hidraulinis rankos dinamometras naudotas rankos plaštakų raumenų jègai ịvertinti.

Tyrimo metu gauti duomenys apdoroti ir analizuoti naudojant IBM SPSS 21 statistini programų paketą ir Microsoft Office Excel 2007. Skaičiuotos šios charakteristikos: imties vidurkis, vidurkio standartinè paklaida (SN), santykiniai dažniai išreikšti procentais, statistinių hipotezių tikrinimui pasirinktas reikšmingumo lygmuo $\mathrm{p}<0,05$. Dviejų nepriklausomų imčių lyginimui taikytas Stjudent'o (Student) t kriterijus, trijų ir daugiau priklausomų imčių lyginimui taikyta blokuotų duomenų ANOVA. Intervaliniams kintamiesiems požymių tarpusavio ryšių stiprumo nustatymui taikytas Pirson`o (Pearson) koreliacijos koeficientas.

\section{Rezultatai ir jų aptarimas}

Tiriamųų grupės pagal amžių buvo homogeniškos. Remiantis gautais rezultatais buvo nustatyta, kad asmenims, patyrusiems GSI, dažnai pasireiškia rankų funkcijos sutrikimai: sumažejusi rankų raumenų jëga, ištvermè. Reabilitacijos eigoje ir tęsiant tyrimą šešis mènesius namuose, visiems tiriamiesiems (dinamometru) buvo matuota pažeistos rankos plaštakos raumenų jèga. Išanalizavę gautus duomenis matome, kad 1 grupès tiriamujjų pažeistos rankos raumenų jëga

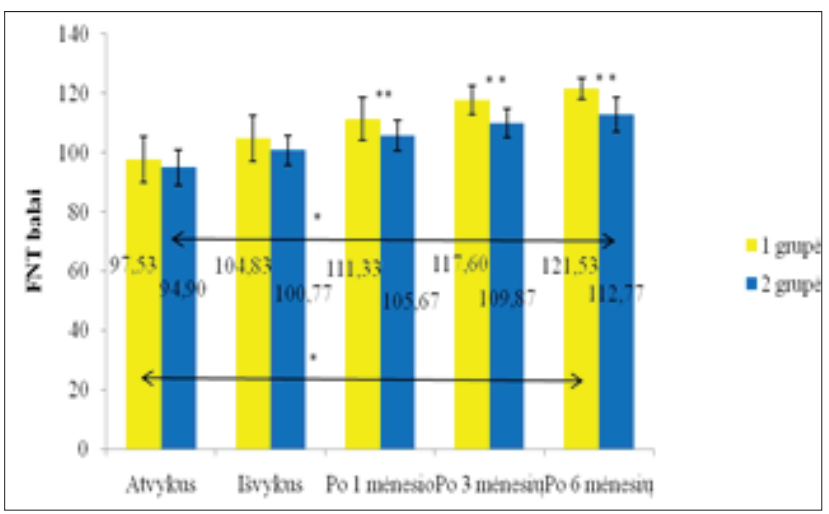

2 pav. Pirmos ir antros grupių tiriamujų savarankiškumo vertinimas reabilitacijos eigoje ir po pusès metų namuose $\left({ }^{*} p<0,05\right)$ 
buvo statistiškai reikšmingai didesnè, nei 2 grupès tiriamujų $(\mathrm{p}<0,05)$, vertinant po 6 ménesių (1 pav.).

Labutytè ir kt. (2008) tyrè dinamometrijos reikšmę motorinès funkcijos atgavimo prognozei po galvos smegenu insulto ir nustaté, kad galūnių raumenų jèga po reabilitacijos padidejjo ir sumažejo jègos disbalansas tarp sveikosios ir pažeistosios pusès (5).

Iš tyrimo metu gautų duomenų nustatyta, jog po taikytos ergoterapijos programos plaštakos raumenų jèga abiejose grupèse padidèjo statistiškai reikšmingai $(p<0,05)$.

Ye Y. it kiti (2014) teigia, jog plaštakos suspaudimo jèga priklauso nuo lenkiančių raumenų sinergijos, riešo ir pirštų sukimo momento santykio. Raumenų jèga siejasi su rankos funkcijos atgavimu, atgaunat rankos funkciją, stebima didesnè rankos raumenų jèga. Šio tyrimo metu gauti rezultatai siejasi su mūsų gautais tyrimo rezultatais, po taikytos ergoterapijos stebimas tiek motorinès rankos funkcijos, tiek ir raumenų jẻgos atgavimas (6).

Lyginant gautus FNT testo duomenis tarp grupių, buvo nustatytas statistiškai reikšmingas pirmos grupès, kuri atliko ergoterapijos namų programą, balų padidejjimas $(\mathrm{p}<0,05)$. Tiriamiesiems, kuriems buvo taikyta ET namų programa, FNT funkcinis nepriklausomumas statistiškai reikšmingai pagerèjo nuo $104,83 \pm 7,70$ balu $(\mathrm{p}<0,05)$ iki $121,53 \pm 3,50$ balų $(p<0,05)$. Jie gebejjo savarankiškai atlikti kasdienes veiklas ir tik atliekant sudètingesnes veiklas (smulkinant maistą ir naudojantis stalo įrankiais, maudantis vonioje ir naudojantis iqvairiomis vonios reikmenimis, persikeliant i vonią) išliko modifikuotos pagalbos būtinybè.

2 grupès tiriamiesiems, kuriems nebuvo taikoma ET programa namuose, savarankiškumas statistiškai reikšmingai pagerejjo nuo $100,77 \pm 5,00$ balų $(p<0,05)$ iki $112,07 \pm 5,77$ $(p<0,05)$ balų. Išliko minimalus kito asmens pagalbos ar priežiūros poreikis ( 2 pav.).

Literatūroje nurodoma, kad asmenims po GSI dažniausiai sutrinka gebėjimas savarankiškai pasinaudoti tualetu, maudytis, lipti laiptais, gebejjimas eiti ar važiuoti vežimèliu bei aprengti apatinę kūno dali (7). Pastebèta, kad reabilitacijos eigoje greičiausiai pagereja gebejjimas savarankiškai valgyti, atlikti asmens higieną, gebejjimas aprengti viršutinę kūno dalị, persikelti iš lovos ị vežimèlị ir atgal, vèliausiai - gebèjimas aprengti apatinę kūno dalì, savarankiškai maudytis bei naudotis tualetu (7). Šio tyrimo metu gauti rezultatai neprieštaravo mūsų gautiems rezultatams.

Tyrimo metu buvo vertinama tiriamujų parezinès rankos miklumas naudojant Frenchay rankos miklumo testą. Buvo atliekamos 5 užduotys ir vertinamas jų atlikimo laikas.

Remdamiesi gautais rezultatais, galime daryti išvadą, kad taikyta ET namų programa turejjo įtakos rankos miklumui atsistatyti, tai puikiai matoma vėlesniuose tyrimo mènesiuose, ypač po 3 mèn. ir po 6 mèn. visose atliktose užduotyse. Nors po atlikto šešių mènesių tyrimo parezinès rankos miklumas statistiškai reikšmingai pagerejo $(p<0,05)$ ir pirmos grupès, ir antros grupès tiriamiesiems, tačiau pir-

1 lentelè. Tiriamųjų parezinès rankos miklumo dinamika viso tyrimo metu

\begin{tabular}{|c|c|c|c|c|c|c|c|c|c|c|}
\hline $\begin{array}{l}\text { Fren- } \\
\text { chay } \\
\text { testas }\end{array}$ & 1 užduotis & $\mathbf{p}$ & 2 užduotis & p & 3 užduotis & p & 4 užduotis & $\mathbf{p}$ & 5 užduotis & p \\
\hline \multicolumn{11}{|c|}{ Atvykus ị reabilitaciją } \\
\hline 1 grupè & $9,86 \pm 1,92$ & \multirow[t]{2}{*}{$\mathrm{p}>0,05$} & $11,86 \pm 2,30$ & \multirow[t]{2}{*}{$\mathrm{p}>0,05$} & $11,16 \pm 2,26$ & \multirow[t]{2}{*}{$\mathrm{p}>0,05$} & $9,53 \pm 1,22$ & \multirow[t]{2}{*}{$\mathrm{p}>0,05$} & $8,86 \pm 0,97$ & \multirow[t]{2}{*}{$\mathrm{p}>0,05$} \\
\hline 2 grupè & $10 \pm 2,03$ & & $11,73 \pm 2,43$ & & $11,05 \pm 2,51$ & & $10,33 \pm 2,23$ & & $9 \pm 0,98$ & \\
\hline \multicolumn{11}{|c|}{ Išvykus po reabilitacijos } \\
\hline 1 grupè & $9,23 \pm 1,61$ & \multirow[t]{2}{*}{$\mathrm{p}>0,05$} & $11 \pm 1,85$ & \multirow[t]{2}{*}{$\mathrm{p}>0,05$} & $9,86 \pm 1,61$ & \multirow[t]{2}{*}{$\mathrm{p}>0,05$} & $8,8 \pm 0,99$ & \multirow[t]{2}{*}{$\mathrm{p}<0,05$} & $8,23 \pm 1,00$ & \multirow[t]{2}{*}{$\mathrm{p}<0,05$} \\
\hline 2 grupè & $9,4 \pm 1,79$ & & $11,26 \pm 2,25$ & & $10,8 \pm 2,34$ & & $9,63 \pm 1,90$ & & $8,63 \pm 0,92$ & \\
\hline \multicolumn{11}{|c|}{ Po 1 mėnesio, namuose } \\
\hline 1 grupė & $8,46 \pm 1,40$ & \multirow[t]{2}{*}{$\mathrm{p}>0,05$} & $9,73 \pm 1,76$ & \multirow[t]{2}{*}{$\mathrm{p}>0,05$} & $8,76 \pm 1,38$ & \multirow[t]{2}{*}{$\mathrm{p}>0,05$} & $8 \pm 0,78$ & \multirow[t]{2}{*}{$\mathrm{p}<0,05$} & $7,46 \pm 0,89$ & \multirow[t]{2}{*}{$\mathrm{p}<0,05$} \\
\hline 2 grupé & $8,73 \pm 1,59$ & & $10,4 \pm 2,20$ & & $10,2 \pm 2,17$ & & $9 \pm 1,66$ & & $7,93 \pm 0,82$ & \\
\hline \multicolumn{11}{|c|}{ Po 3 mėnesių, namuose } \\
\hline 1 grupè & $7,6 \pm 0,96$ & \multirow[t]{2}{*}{$\mathbf{p}<\mathbf{0 , 0 5}$} & $8,4 \pm 1,65$ & \multirow[t]{2}{*}{$\mathrm{p}<0,05$} & $7,83 \pm 1,20$ & \multirow[t]{2}{*}{$\mathrm{p}<0,05$} & $7 \pm 0,98$ & \multirow[t]{2}{*}{$\mathrm{p}<0,05$} & $6,7 \pm 0,87$ & \multirow[t]{2}{*}{$p<0,05$} \\
\hline 2grupè & $8,3 \pm 1,57$ & & $9,63 \pm 1,95$ & & $9,53 \pm 2,19$ & & $8,43 \pm 1,79$ & & $7,46 \pm 0,93$ & \\
\hline \multicolumn{11}{|c|}{ Po 6 mėnesių, namuose } \\
\hline 1 grupė & $6,9 \pm 0,95$ & \multirow[t]{2}{*}{$p p<0,05$} & $7,36 \pm 1,58$ & \multirow[t]{2}{*}{$\mathbf{p}<\mathbf{0 , 0 5}$} & $7,33 \pm 1,24$ & \multirow[t]{2}{*}{$\mathrm{p}<0,05$} & $6,33 \pm 0,92$ & \multirow[t]{2}{*}{$\mathrm{p}<0,05$} & $5,93 \pm 0,63$ & \multirow[t]{2}{*}{$p<0,05$} \\
\hline 2 grupè & $7,76 \pm 1,54$ & & $8,63 \pm 1,47$ & & $8,96 \pm 1,88$ & & $7,93 \pm 1,76$ & & $6,86 \pm 0,93$ & \\
\hline
\end{tabular}


mos grupès tiriamujų Frenčeij‘o (Frenchay) testo atlikimo rezultatai buvo nežymiai, bet geresni, nei antros grupès, kurie ergoterapijos programos neatliko (1 lentelè).

Vertinant sąsajas tarp kairès (parezinès) rankos raumenu jëgos ir Frenchay rankos miklumo testo užduočių, buvo nustatytas atvirkštinès priklausomybès, vidutinio stiprumo ryšys. Gerèjant plaštakos funkcijai ir didejjant jos raumenų jègai, gereja Frenchay rankos miklumo testo rezultatai bei trumpèja užduočių atlikimo laikas.

Analizuojant tiriamujų, patyrusių galvos smegenų insultą, funkcinio nepriklausomumo (FNT) ir Frenchay rankos miklumo testo užduotis, taip pat buvo nustatytas atvirkštinès priklausomybès, vidutinio stiprumo ryšys. Didejjant FNT testo rezultatams (gerejjant savarankiškumui) gerejja ir Frenchay rankos miklumo testo atlikimo laikas. Visas užduotis pacientai atliko per trumpesnị laiką (3 lentelè). Kossi O, Batcho CS ir kiti autoriai (2016) taip pat atliko išsamų šešių mėnesių tyrimą. Paaiškejjo, kad per pirmuosius šešis mėnesius po patirto galvos smegenų insulto net apie 50 procentų atsistato funkcinis savarankiškumas. Tyrimo pradžioje pacientai (16 proc.) buvo iš dalies visiškai priklausomi nuo kitų ir negalèjo atlikti daugumos kasdienių veiklų. Po 6 mènesių didžioji dalis pacientų (67 proc.) jau gebejjo atlikti tam tikras kasdienes veiklas, tačiau vis dar turejjo sunkumų vaikštant ir atliekant veiksmus, kurie reikalauja rankų miklumo (8).

Rankos funkciją taip pat tyrè C.M. Chen ir kiti autoriai (2015), jie pabrèžè rankos funkcijos svarbą ir ịtaką asmens savarankiškumui, gyvenimo kokybei. Jų išvadose buvo teigiama, jog yra daugybé veiksnių turinčių ịtakos asmenų, patyrusių GSI, savarankiškumui ir su juo susijusia gyvenimo kokybe, tačiau vienas pagrindinių - rankos funkcijos atsigavimas (9).

\section{Išvados}

1. Visiems tiriamiesiems po pusès metų nustatytas statistiškai reikšmingas savarankiškumo pagerèjimas $(\mathrm{p}<0,05), 1$ grupès tiriamieji gebejjo savarankiškai atlikti kas-
2 lentelẻ. Sąsajos tarp tiriamujų pažeistos rankos raumenų jėgos ir Frenchay rankos miklumo testo rezultatu

\begin{tabular}{|l|l|l|l|l|l|}
\hline Rodiklis & $\begin{array}{l}\text { Frenchay } \\
\mathbf{1} \text { užd. }\end{array}$ & $\begin{array}{l}\text { Frenchay } \\
\mathbf{2} \text { užd. }\end{array}$ & $\begin{array}{l}\text { Frenchay } \\
\mathbf{3} \text { užd. }\end{array}$ & $\begin{array}{l}\text { Frenchay } \\
\mathbf{4} \text { užd. }\end{array}$ & $\begin{array}{l}\text { Frenchay } \\
\mathbf{5} \text { užd. }\end{array}$ \\
\hline $\begin{array}{l}\text { Dinamometrija } \\
\text { Parezinė ranka } \\
\text { r reikšme் }\end{array}$ & $\mathrm{r}=-0,60$ & $\mathrm{r}=-0,50$ & $\mathrm{r}=-0,65$ & $\mathrm{r}=-0,66$ & $\mathrm{r}=-0,61$ \\
\hline p reikšme் & $* \mathrm{p}<0,001$ & $* \mathrm{p}<0,001$ & $* \mathrm{p}<0,001$ & $* \mathrm{p}<0,001$ & $* \mathrm{p}<0,001$ \\
\hline
\end{tabular}

3 lentelė. Sąsajos tarp tiriamųjų savarankiškumo ir Frenchay rankos miklumo testo rezultatu

\begin{tabular}{|l|l|l|l|l|l|}
\hline Rodiklis & $\begin{array}{l}\text { Frenchay } \\
\mathbf{1} \text { užd. }\end{array}$ & $\begin{array}{l}\text { Frenchay } \\
\mathbf{2} \text { užd. }\end{array}$ & $\begin{array}{l}\text { Frenchay } \\
\mathbf{3} \text { užd. }\end{array}$ & $\begin{array}{l}\text { Frenchay } \\
\mathbf{4} \text { užd. }\end{array}$ & $\begin{array}{l}\text { Frenchay } \\
\mathbf{5} \text { užd. }\end{array}$ \\
\hline $\begin{array}{l}\text { FNT } \\
\text { r reikšme் }\end{array}$ & $\mathrm{r}=-0,54$ & $\mathrm{r}=-0,45$ & $\mathrm{r}=-0,64$ & $\mathrm{r}=-0,60$ & $\mathrm{r}=-0,51$ \\
\hline p reikšme் & $* \mathrm{p}<0,001$ & $* \mathrm{p}<0,001$ & $* \mathrm{p}<0,001$ & $* \mathrm{p}<0,001$ & $* \mathrm{p}<0,001$ \\
\hline
\end{tabular}

dienes veiklas ir tik atliekant sudètingesnes veiklas, išliko modifikuotos pagalbos būtinybè, o 2 grupès tiriamiesiems išliko minimalios/vidutinès kito asmens pagalbos poreikis.

2. Visiems tiriamiesiems po pusès metų rankos miklumas statistiškai reikšmingai pagerèjo $(\mathrm{p}<0,05)$.

3. Abiejų grupių tiriamiesiems po pusès metų rankų raumenų jèga statistiškai reikšmingai padidejo $(\mathrm{p}<0,05)$. Taip pat nustatytas statistiškai reikšmingas skirtumas tarp grupių po 6 menesių.

4. Nustatyta, kad rankų miklumas statistiškai reikšmingai siejasi su parezinès rankos plaštakos raumenų jèga ir su pacientu savarankiškumu atliekant kasdienes veiklas.

\section{Literatūra}

1. Gaidelytė R., Želvienė A., Jaselionienè J. Lietuvos sveikatos statistika. Higienos instituto sveikatos informacijos centras. Vilnius, 2015; 5.

2. Judi Edmans, Occupational therapy and stroke. 2010; ISBN 978-1-4051-9266-8.

3. Juocevičius A., Jamontaitė I. E, Janonienė D., Glamba V., Danys A. Sergančių galvos smegenų insultu pacientų, reabilituotų trijose reabilitacijos paslaugas teikiančiose įstaigose, charakteristika. Gerontologija, 2010; 10(4): 214-22.

4. Sudmantienė D., Žiliukas G., Drungilienė D. ir kt. Stacionarinès reabilitacijos ittaka persirgusių galvos smegenų insultu ligos eigai. Sveikatos mokslai, 2013; 23 (1):138-142.

https://doi.org/10.5200/sm-hs.2013.025

5. Labutytė R., Zachovajevienė B., Venckūnas T. Dinamometrijos reikšmè motorinès funkcijos atgavimo prognozei sveikstant po galvos smegenu infarkto. Medicinos teorija ir praktika, 2008; 14(4): 313-321.

6. Ye Y, Ma L, Yan T, Liu H, Wei X, Song R. Kinetic measurements of hand motor impairments after mild to moderate stroke using grip control tasks. Journal of neuroengineering and reabilitation 2014; 84(11): 2-10.

https://doi.org/10.1186/1743-0003-11-84

7. Sale P, Ceravolo MG, Franceschini M. Action observation therapy in the subacute 
phase promotes dexterity recovery in right-hemisphere stroke patients. BioMed Research International 2014; (1): 1-7. https://doi.org/10.1155/2014/457538

8. Kossi O, Batcho CS, Adoukonou T, Thonnard JL. Functional recovery after stroke in Benin: a six-month follow-up study. J Rehabil Med 2016 Oct 5; 48(8):671-675. https://doi.org/10.2340/16501977-2128

9. Chen CM, Tsai CC, Chung CY, Chen CL, Wu KP, Chen HC. Potential predictors for health-related qualit of life in stroke patients undergoing inpatient rehabilitation. From National Library of Medicine cited 2017-04-20 [online]. Avaible from Internet:http://www.ncbi.nlm.nih.gov/pubmed/15823991

\section{INVESTIGATION OF THE PATIENTS DAILY ACTIVITIES AFTER EXPERIENCING STROKE AND DAMAGED ARM WHILE APPLYING AND OCCUPATIONAL THERAPY AT HOME}

\section{J. Rapolienė, L. Pivorienè}

Key words: occupational therapy, occupational therapy home program, stroke, left arm hemiparesis, independence in daily activities, arm muscle strength.

Summary

Stroke - is a disease causing blood flow in the brain. It caused by a cerebrovascular disorder, heart disease or diabetes mellitus (1). In most countries population, the most common causes of death are chronic noncommunicable diseases (NCD), particularly cardiovascular disease (CVD).

The most common consequence of stroke is paralysis of one side of the body, resulting in developing coordination, balance, movement disorders.

The situation of patients occupational therapy after experiencing stroke is being analysed, however there is little knowledge and data, concerning the change in daily activities as well as the functioning of the damaged arm not only during the rehabilitation process, but also while continuing occupationaltherapy at home.
The aim of the paper is to evaluate the situation of patients ability to perform daily activities as well as the performance of the damaged arm after experiencing stroke, during the rehabilitation process and occupational therapy at home.

Material and methods. The study included 60 patients who were diagnosed with stroke in the right hemisphere of the brain. Patients were divided: group $1, \mathrm{n}=30$ subjects were made up of occupational therapy home program and group $2 \mathrm{n}=30$ subjects returned to the house and had only daily activities without additional occupational therapy program.

The study was carried out from 2016. August - 2017. January. All subjects were applied - Questionnaire, Functional Independence Measure (FIM), dynamometry, Frenchay test.

Results. Patients experienced stroke affected arm muscle strength is restored quickly, using occupational therapy home program with additional occupational therapy tasks.

Conclusions. All subjects after six months showed a statistically significant improvement in self-sufficiency $(\mathrm{p}<0.05)$, group 1 subjects were able to perform daily activities independently and only in more complex activities remained necessary modified aid, and group 2 subjects remained minimal/medium of another person support. All subjects after half a year hand dexterity statistically significant improvement $(\mathrm{p}<0.05)$. In both treatment groups after half a year, hand muscle strength significantly increased $(\mathrm{p}<0.05)$. There was also a statistically significant difference between the groups after 6 months. It was found that manual dexterity statistically significantly associated with parezis hand muscle strength and patient autonomy in everyday activities.

Correspondence to: laurapivoriene001@gmail.com

Gauta 2017-05-05 